\title{
Evaluation of Floods and Landslides Triggered by a Meteorological Catastrophe (Ordu, Turkey, August 2018) Using Optical and Radar Data
}

\author{
Sultan Kocaman $\mathbb{D}^{1},{ }^{1}$ Beste Tavus $\mathbb{D}^{1},{ }^{1}$ Hakan A. Nefeslioglu $\left(\mathbb{D},{ }^{2}\right.$ Gizem Karakas $\mathbb{D}^{\circ},{ }^{1}$ \\ and Candan Gokceoglu $\mathbb{i D}^{2}$
}

${ }^{1}$ Dept. of Geomatics Engineering, Hacettepe University, 06800 Beytepe Ankara, Turkey

${ }^{2}$ Dept. of Geological Engineering, Hacettepe University, 06800 Beytepe Ankara, Turkey

Correspondence should be addressed to Sultan Kocaman; sultankocaman@hacettepe.edu.tr

Received 31 July 2020; Revised 18 October 2020; Accepted 10 December 2020; Published 23 December 2020

Academic Editor: Nejan Huvaj Sarihan

Copyright $\odot 2020$ Sultan Kocaman et al. This is an open access article distributed under the Creative Commons Attribution License, which permits unrestricted use, distribution, and reproduction in any medium, provided the original work is properly cited.

\begin{abstract}
This study explores the potential of photogrammetric datasets and remote sensing methods for the assessment of a meteorological catastrophe that occurred in Ordu, Turkey in August 2018. During the event, flash floods and several landslides caused losses of lives, evacuation of people from their homes, collapses of infrastructure and large constructions, destruction of agricultural fields, and many other economic losses. The meteorological conditions before and during the flood were analyzed here and compared with long-term records. The flood extent and the landslide susceptibility were investigated by using multisensor and multitemporal data. Sentinel-1 SAR (Synthetic Aperture Radar), Sentinel-2 optical data, and aerial photogrammetric datasets were employed for the investigations using machine learning techniques. The changes were assessed both at a local and regional level and evaluated together with available damage reports. The analysis of the rainfall data recorded during the two weeks before the floods and landslides in heavily affected regions shows that the rainfall continued for consecutive hours with an amount of up to $68 \mathrm{~mm} /$ hour. The regional level classification results obtained from Sentinel-1 and Sentinel-2 data by using the random forest $(\mathrm{RF})$ method exhibit $97 \%$ accuracy for the flood class. The landslide susceptibility prediction performance from aerial photogrammetric datasets was $92 \%$ represented by the Area Under Curve (AUC) value provided by the RF method. The results presented here show that considering the occurrence frequency and immense damages after such events, the use of novel remote sensing technologies and spatial analysis methods is unavoidable for disaster mitigation efforts and for the monitoring of environmental effects. Although the increasing number of earth observation satellites complemented with airborne imaging sensors is capable of ensuring data collection requirement with diverse spectral, spatial, and temporal resolutions, further studies are required to automate the data processing, efficient information extraction, and data fusion and also to increase the accuracy of the results.
\end{abstract}

\section{Introduction}

Natural hazards such as floods, earthquakes, and landslides occur at various frequencies on the Earth. Over the last twenty years, 7,348 natural hazard-related disasters were recorded worldwide by EM-DAT (Emergency Events Database), one of the foremost international databases of such events. In total, disasters claimed approximately 1.23 million lives, an average of 60,000 per annum, and affected a total of over 4 billion people (many on more than one occasion); and these numbers represent a sharp increase in the number of recorded disaster events when compared with the previous twenty years [1]. With increasing anthropogenic activities and climate change, the number and effects of landslide and flooding events are also rising. Breugem et al. [2] discussed the influences of global warming on heavy precipitation events and stated that they have been intensified and can be a fingerprint of the impacts of climate change. Such extreme events are expected to occur more frequently due to global warming [3] and pose risk for severe floods [4]. The return 
period of natural hazards in Turkey is quite high due to the geological and geomorphological conditions (e.g., high seismicity, young and steep topography, being climatological transition area, and weak lithological elements). Due to the rapid urbanization and industrialization, which expand urban areas and increase transportation structures, multidisciplinary research projects should be carried out in order to reduce the losses of properties and lives sourced from natural disasters.

The extreme precipitation events have short durations. In order to predict the precipitation extreme accurately and to respond to changes in the risk of floods adequately, their monitoring and modeling with high spatial and temporal resolution are needed $[2,5]$. Investigations on the conditions of occurrence, period, magnitude, and severity of a natural hazard and identification of possible consequences are crucial to prevent future hazards from turning into natural disasters. Conventionally, such studies have been performed by fieldwork of geologists and geomorphologists (e.g., [6]), while they should be performed without interruption to reduce the investment costs, to increase the service life, to ensure sustainable environmental protection, and to increase the living quality. Examples to the investigations on various landslides triggered by rainfall exist in the literature (e.g., [7-9]). However, the data collection in large areas and mountainous regions is time-consuming, difficult, and even impossible. In addition, proper site selection for settlements and transportation structures is an exhaustive process and can be nonviable with conventional methods. Therefore, the use of geospatial technologies, and in particular remote sensing and photogrammetric techniques to obtain fast and accurate results, is needed.

Flood events are often caused by heavy rainfall, snow melting, dam failure, and lake or river overflows [10-12]. The factors such as lack of proper infrastructure development, rapid urbanization, and insufficient consideration of environmental and climate conditions cause the flood hazard to be more destructive [13-16]. Since the consequences of floods depend highly on the location, the extent, and the depth of the flood, it is very important to know the surface properties and to evaluate all parameters in the event of flood.

Landslide is also one of the most common and destructive natural hazards. As an example, a total of 23,041 landslides were enlisted in Turkey between 1950 and 2018 [17]. It is necessary to generate landslide inventories and to identify landslide-prone areas, in order to support regional land use and infrastructure planning and to increase the awareness for natural hazards and risks. Therefore, the preparation of accurate and up-to-date landslide susceptibility and hazard maps is of great importance for landslide hazard mitigation efforts. Among commonly observed triggering factors for landslides, extreme precipitation and earthquakes can be listed (see, e.g., [18-21]), which also cause debris slides and flows (e.g., [22]).

Although the different geodata collection platforms (i.e., spaceborne, airborne, and terrestrial) provide great flexibility in data acquisition times and viewing geometries, and the sensor types are diverse (e.g., SAR (Synthetic Aperture Radar), optical, Light Detection and Ranging (LiDAR),
Global Navigation Satellite System (GNSS), and smartphones), new algorithmic approaches can exploit their potential by ensuring efficient data integration. Thus, the efficiency and the reliability of the results can be increased for many applications including environmental monitoring and disaster management. Earth observation (EO) data from space is very useful in various stages of disaster mitigation efforts by providing information without direct contact with the hazard-prone region. Satellite optical and radar sensors are primary data providers for the flood assessment and monitoring. The EO datasets obtained from optical and SAR sensors are often employed for flood extent mapping in the literature. When these two types of sensors are compared, identification of flood extent from optical images is easier due to the different radiometric responses of water surfaces [23]. Various techniques such as single-band thresholding, spectral water indices [24], segmentation and classification [25, 26], and fusion [27] have been applied for flood extraction from optical data in the literature. Since optical imaging is affected by the cloud cover, which limits their usability for flood mapping, they are used for postflood analysis mostly [28]. With the increased temporal and spatial availability of SAR data, this technology has become a valuable information source for flood mapping. SAR systems penetrate the clouds and do not need sunlight for operation; and thus, they can provide important advantages in obtaining accurate flood information. Different methods have been used for flood mapping using SAR data in the literature, such as visual interpretation [29], histogram thresholding [30, 31], supervised classification [32, 33], automatic segmentation [34], region growing [35], change detection [36], and interferometric SAR coherence [37]. Lal et al. [38] included also rainfall data together with SAR and optical satellite data for evaluating extreme flood hazard events in Kerala, India. On the other hand, as a high-resolution geodata source, aerial photogrammetric techniques can provide the required timely 3D datasets for regional landslide susceptibility and hazard assessments with centimetre or decimeter level accuracy. Unlike optical satellite images, aerial stereo images can be taken subsequent to a hazard with better flexibility for the time of acquisition and are affected less by clouds. However, EO satellites can provide data regularly with a large swath, such as Sentinel-1 and Sentinel-2 missions of the European Space Agency (ESA [39]).

Landslides and floods have been frequently encountered in the Black Sea Region of Turkey [7, 9, 40-43], which cause serious loss of lives and properties. In August 2018, a catastrophic meteorological event in Ordu Province located in the Black Sea Region occurred, which resulted in flash floods and triggered landslides. Consequently, the flash flood and the landslides caused several deaths and injuries. Many infrastructure elements, such as bridges, roads, and houses, were collapsed or damaged by the flood and/or the landslides. The landslides triggered by the meteorological event caused serious damages on hazelnut gardens, buildings, and enforced evacuations of villages. The aims of the present study are to investigate different aspects of this catastrophic meteorological event by employing photogrammetric techniques, to demonstrate the usability of multisensor remote sensing data for the pre- and postdisaster assessments, and 
to produce landslide susceptibility and flood extent maps of the selected substudy areas. The geological and geomorphological characteristics of the area were investigated with the help of photogrammetric datasets to assess the landslideprone regions in a subpart of the study site. The potential of the Sentinel-1 and Sentinel-2 datasets, which were obtained under wet and dry weather conditions, was investigated to map and to analyze the flood event. In addition, aerial photogrammetric flight datasets were processed in $3 \mathrm{D}$ to prepare the landslide inventory and to produce landslide susceptibility map in a part of the study area. With the approach developed here, data of the past could be related and interpreted, and practical and reliable data collection and processing methods were proposed for the future that allows monitoring of the changes. Additionally, the results obtained from the present study can be used for land-use planning and suitable site selection works for infrastructures; and hence, this will contribute to natural disaster mitigation efforts.

\section{Study Area}

The study area is located in Ordu Province and covers parts of Terme and Carsamba districts of Samsun Province as well. Both provinces are located in the northern part of Turkey, in Black Sea Region. Figure 1 shows the location of the study area, the subareas used for the evaluation of the results, and the locations and altitudes of meteorological stations. Ordu Province has a long coastal part (ca. $100 \mathrm{~km}$ ) with mostly sand beaches. A wet climate dominates in the region with rainfall throughout the year. There are 36 major and minor streams in Ordu, and the most commonly observed natural hazards in the area between 1950-2011 were mass movements (i.e., landslide and rockfall) (88\%) and floods (9\%) [44].

The stratigraphic sequence begins with the Late Cretaceous-aged dacite, rhyolite, rhyodacite, and undifferentiated andezite, pyroclastics, and continues with Late Cretaceous-Eocene aged clastics and carbonates in the study area (Figure 2). Paleocene-Eocene aged granitoids intrudes into Late Cretaceous-Eocene aged units in the region. Volcanic rocks developed due to the volcanism active during the Middle Eocene and Late Eocene periods and are also observed in the study area. Volcanic rocks in humid climatic environments are highly sensitive to weathering. In the region, a thick regolith zone on the volcanic rocks exists, and this zone is prone to landsliding. The weak sedimentary rocks in the region are also susceptible to landsliding. The Eocene aged clastics and carbonates are observed together with the Middle-Late Eocene aged volcanics and sedimentary rocks [45].

According to the damage report published by the Turkish State Meteorological Service, stream beds overflowed due to heavy rainfall in the Ordu province on August 02, 2018, and flooded in low-rise buildings. Due to heavy rainfall, transportation was disrupted in some areas and partial collapses occurred on highways. Cevizdere District of Unye overflowed and destroyed two bridges and interrupted the transportation between Ordu and Samsun cities for some time (Figures 3(a) and 3(b)). The flooding caused damages in the basements of hundreds of buildings (Figures 3(c) and 3(d)).
Ordu area is one of the most important hazelnut producers in the world. Hazelnut harvests in the towns of Ikizce, Caybaşı, Unye, Fatsa, and Carsamba were flooded, and heavy damages occurred in hazelnut gardens and other agricultural lands (Figures 3(e) and 3(f)). The three days of almost nonstop precipitation in Ikizce district was classified as "violent rain" according to the Glossary of Meteorology [47]. Landslides occurred in the region as a result of excessive and prolonged rainfall. One person died due to the landslide. It also caused damages on the roads and in the villages as well (Figures 3(g) and 3(h)).

\section{Materials and Methods}

A methodological workflow is proposed here to assess the landslide susceptibility and the flood extent based on the availability and the characteristics of the existing geospatial datasets. The overall methodological workflow of the study given in Figure 4 consists of three main sections: flood extent mapping by using SAR and optical remote sensing data, landslide inventory and susceptibility map production using high-resolution aerial photogrammetric datasets, and the statistical analysis of short and long-term meteorological data. In the first part, meteorological data provided by the Turkish State Meteorological Service for a total of 12 stations in Samsun and Ordu Provinces were analyzed. In the second part, Sentinel-1 SAR data and Sentinel-2 optical data were used for the generation of flood extent maps. In the last part, aerial photogrammetric images were used to produce landslide susceptibility maps. Details on each part are given in the following subsections.

3.1. Analysis of Meteorological Data. Precipitation data of 12 stations were analyzed to comprehend the meteorological conditions of the two weeks of extreme rainfall period, in which floods occurred. The locations and the altitudes of the stations are shown in Figure 1. The altitudes of the meteorological stations range between $5 \mathrm{~m}$ and $790 \mathrm{~m}$. Among those, Ordu and Unye Meteorological Stations are the oldest and have records since 1959 except for a few years of gaps (no measurement available). The yearly precipitations of both stations are presented in Figure 5 including long-term averages. The average annual precipitation value of Ordu is $1045.2 \mathrm{~mm}$ while that of Unye is $1175.3 \mathrm{~mm}$. From Figure 5, it can be seen that although the yearly precipitation value of Ordu is close to the long-term average for 2018, Unye has one of the highest values $(1527.6 \mathrm{~mm})$ in its history for this year.

The monthly total precipitation values in 2018 are given in Figure 6 together with long-term monthly averages calculated based on 61 and 60 years measurements between 1959 and 2019 for Ordu and Unye, respectively. Again, although Ordu values exhibit high similarity to the long-term averages, Unye monthly precipitation values are significantly higher especially for July (2.5 times), August (1.9 times), and September (2.8 times). It is evident that the heavy rainfall affected the western parts of the area considered in the study.

Two flood events were recorded in the region on August 2nd and 8th, with the latter one being much more 


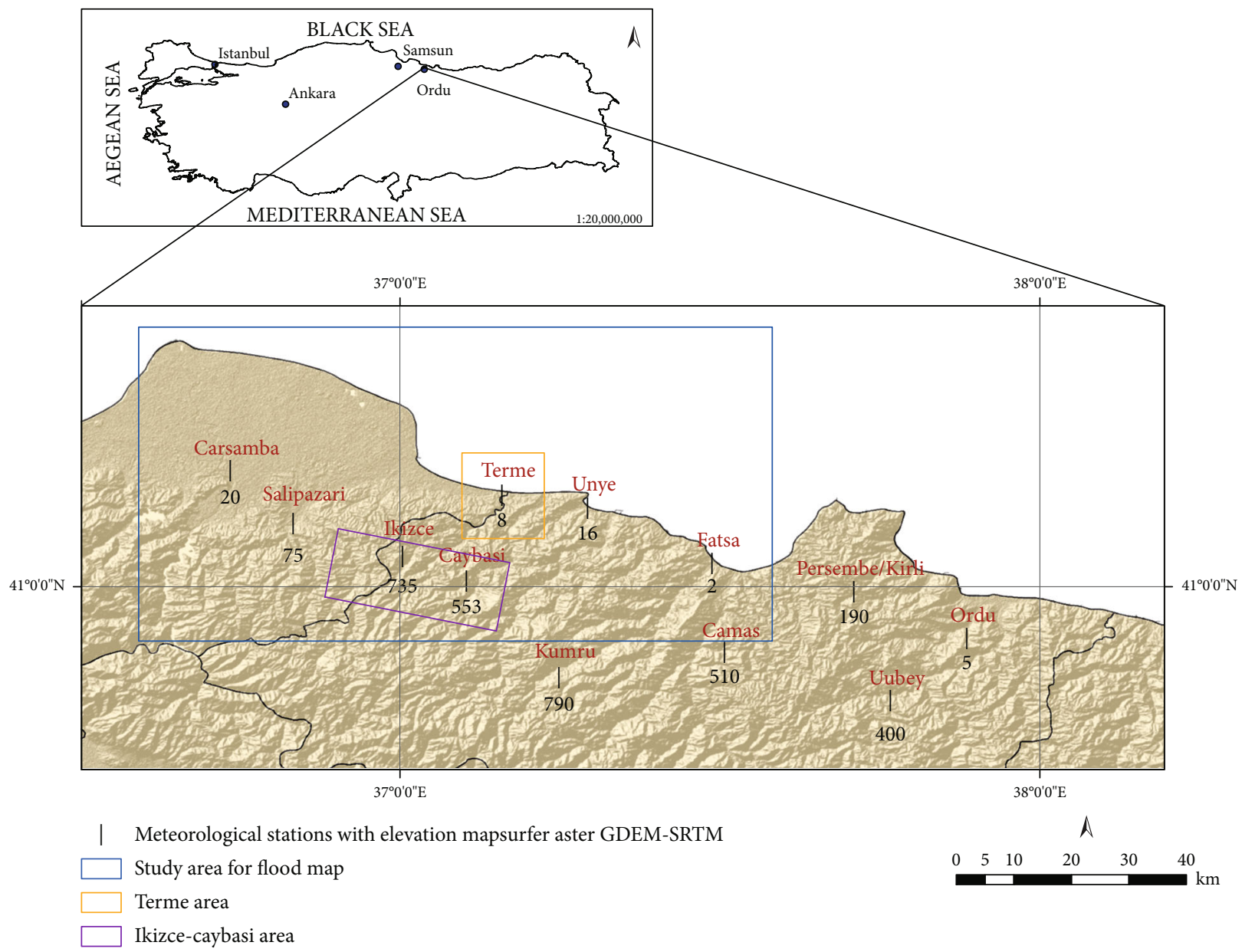

Figure 1: Location of the study area and subareas used for evaluation of the resulting flood map (study area coordinates: upper left: $36^{\circ} 35^{\prime} 13^{\prime \prime}$ E, $41^{\circ} 25^{\prime} 01^{\prime \prime} \mathrm{N}$; lower right: $37^{\circ} 36^{\prime} 11^{\prime \prime} \mathrm{E}, 40^{\circ} 47^{\prime} 45^{\prime \prime} \mathrm{N}$ ).

destructive. Daily precipitation values between 1 and 15 August 2018 are provided in Figure 7 cumulatively. Extreme precipitation on the days of 8th and 9th of August is clearly visible in the Figure especially for Caybasi-Ikizce area, Persembe, Terme, Fatsa, Unye, and Salipazari districts. Very high hourly rainfall for the same districts was observed for consecutive hours (Figure 8). When the rainfall data is closely inspected, the higher rainfall values were recorded at the western parts of the study area. In addition, the intense rainfall occurred at higher altitudes. Rainfall at high altitudes caused floods at low altitudes and damaged the settlements and infrastructure here. In addition, prolonged rainfall saturated the slope material and triggered the landslides. Especially, the landslides were triggered by August 8, 2018, rainfall because some of the August 2, 2018, rainfall infiltrated and saturated the regolith and the weak zones on the slopes; and the August 8, 2018, rainfall triggered the saturated slope material. In addition, the maximum rainfall intensity of the August 2, 2018, rainfall was about $50 \mathrm{~mm}$ /hour while that of the August 8, 2018, rainfall was about $70 \mathrm{~mm}$ (Figure 8 ). With the prolonged heavy rainfall on August 8 and 9,2018, floods and landslides were triggered at the same time, which increased the destructive effects of the floods at the lower altitudes.
3.2. Flood Extent Mapping by Employing Optical and Radar Remote Sensing Data. Since the visual interpretation of optical data is an easier task when compared with SAR data, a feature level data fusion approach was employed here for flood extent mapping. Since both datasets were geometrically aligned (coregistered), the training areas (polygons) collected from Sentinel-2 images were utilized also for Sentinel-1 data. Sentinel-1B SAR and Sentinel-2A/2B data obtained from ESA Copernicus Open Access Hub [49] were used in this study for flood extent mapping using the Sentinel Application Platform (SNAP) Tool of ESA [50]. Sentinel-1 is a constellation composed of two satellites, i.e., Sentinel-1A and Sentinel-1B, operating at the same orbit with a joint revisit time of 6 days (12 days each) [51]. The SAR sensors acquire data from C-band with $\triangle 5.7 \mathrm{~cm}$ wavelength and have a swath-width of $250 \mathrm{~km}$ and spatial resolution of $5 \mathrm{~m} \times 20 \mathrm{~m}$ in the IW mode. The Sentinel-2 constellation contains Sentinel-2A and Sentinel-2B satellites, which are twins and has a joint revisit time of five days [52]. The MultiSpectral Instruments (MSI) aboard Sentinel-2 satellites takes images with pushbroom principle with a swath-width of $290 \mathrm{~km}$. Each MSI has 13 spectral bands covering visible, red-edge, near-infrared (NIR), and short-wave infrared (SWIR) wavelengths with spatial resolutions ranging between $10 \mathrm{~m}$ and 


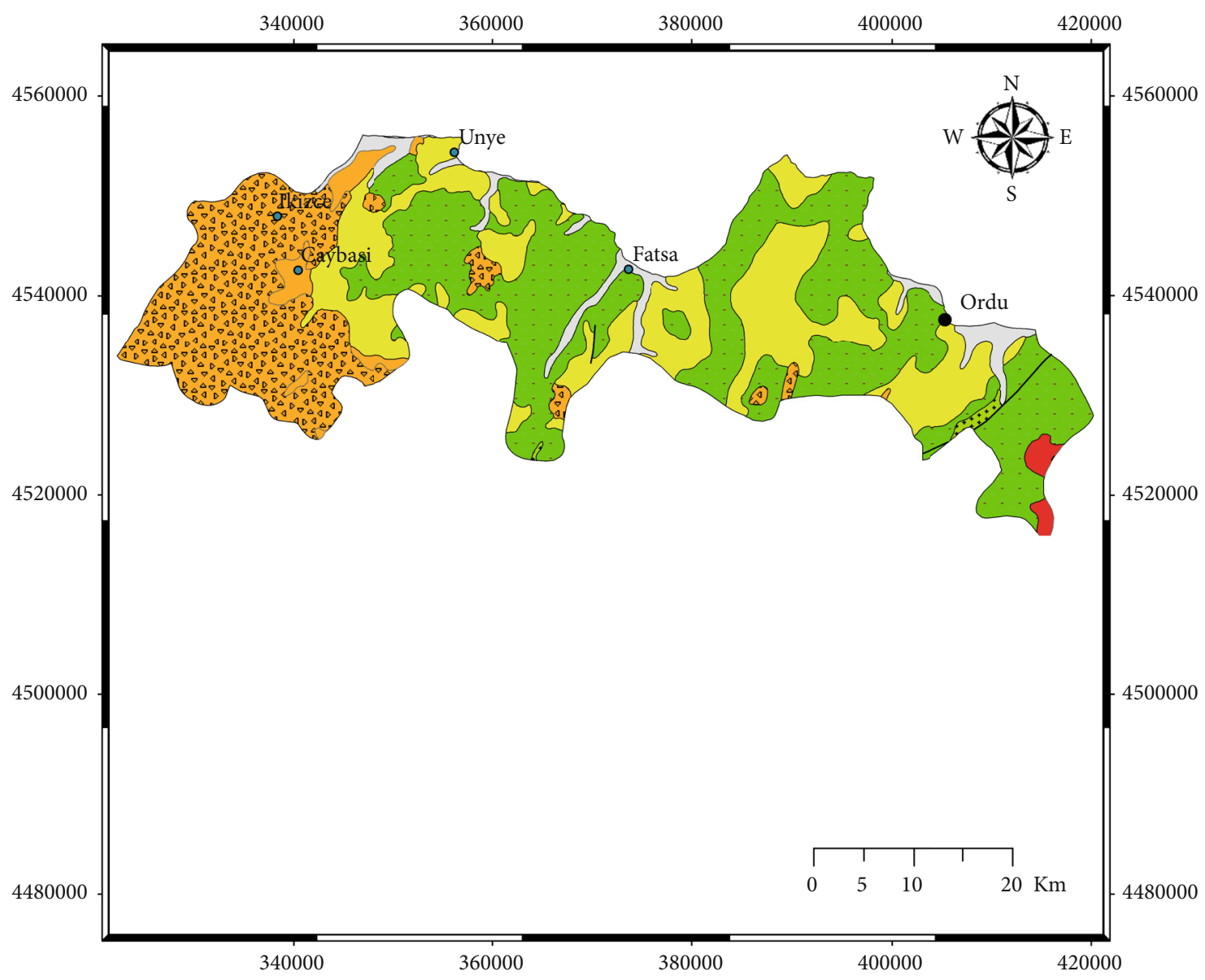

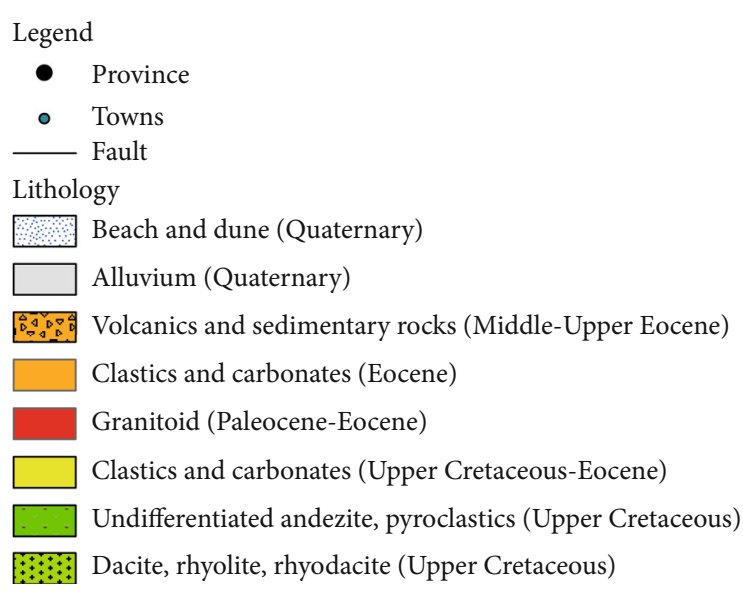

Figure 2: Geological characteristics of the study area [46].

$60 \mathrm{~m}$. The absolute geolocation specification for Sentinel-2 provided by ESA is $20 \mathrm{~m}$. However, Pandžic et al. [53] reported even higher accuracy, which was better than $10 \mathrm{~m}$, in their tests over Serbia and Austria.

The datasets used in the study intercept the during- and postdisaster conditions. Two Sentinel-1B datasets, DS1 and DS2, taken on August 10, 2018, were the closest available to the flood date and were obtained in interferometric wide (IW) swath mode with dual polarization (VV and $\mathrm{VH}$ ). The Sentinel-2B MSI image (DS3) was acquired on August 9th during the flood and was partially cloudy. The Sentinel-
2A MSI imagery (DS4) was taken on October 3, 2018, (after the flood) and is almost cloud-free. Level 2 products of Sentinel-2, which are terrain-corrected, were processed here. Both SAR and optical data were preprocessed before feature extraction for calibration, radiometric enhancement (e.g., speckle filtering and cloud masking), and the removal of geometric distortions and alignment differences (i.e., terrain correction, coregistration, and resampling). The Sentinel-2 data were resampled to $10 \mathrm{~m}$ in SNAP software using the bilinear interpolation method. Further details on the preprocessing steps applied here can be found in Tavus et al. [54]. 


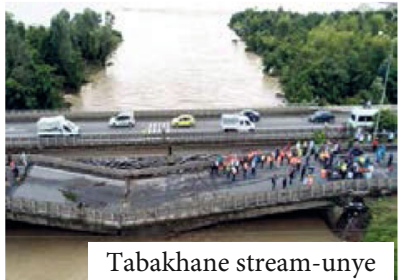

(a)

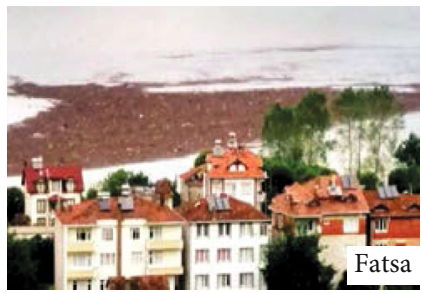

(e)

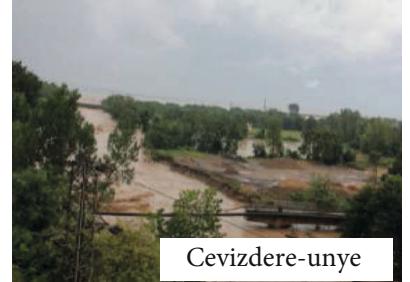

(b)

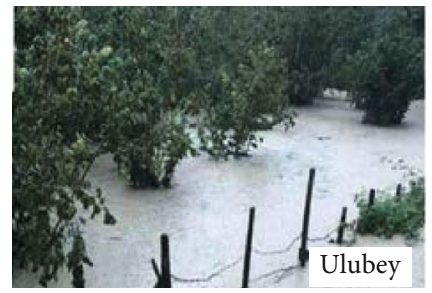

(f)

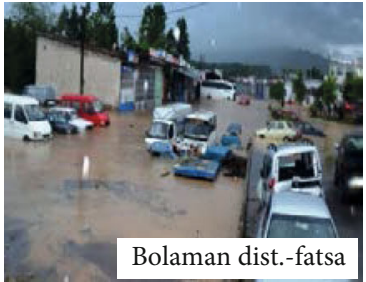

(c)

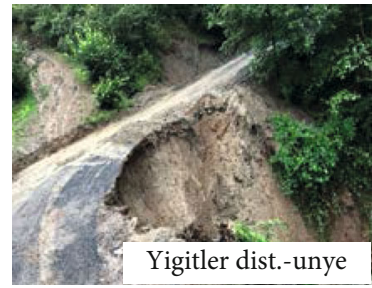

(g)

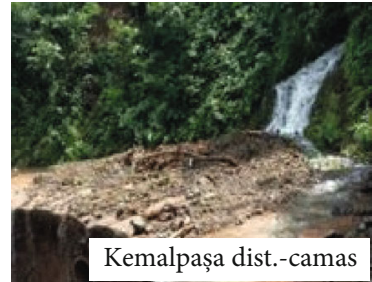

(d)

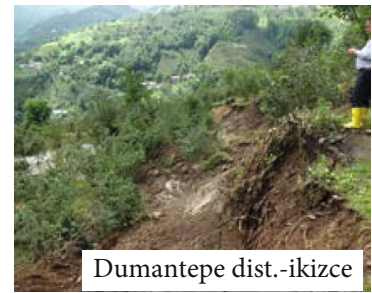

(h)

FIgure 3: Some examples to the damages after Aug 8th, 2018, flood in Ordu (photo credits: TRT [48]).

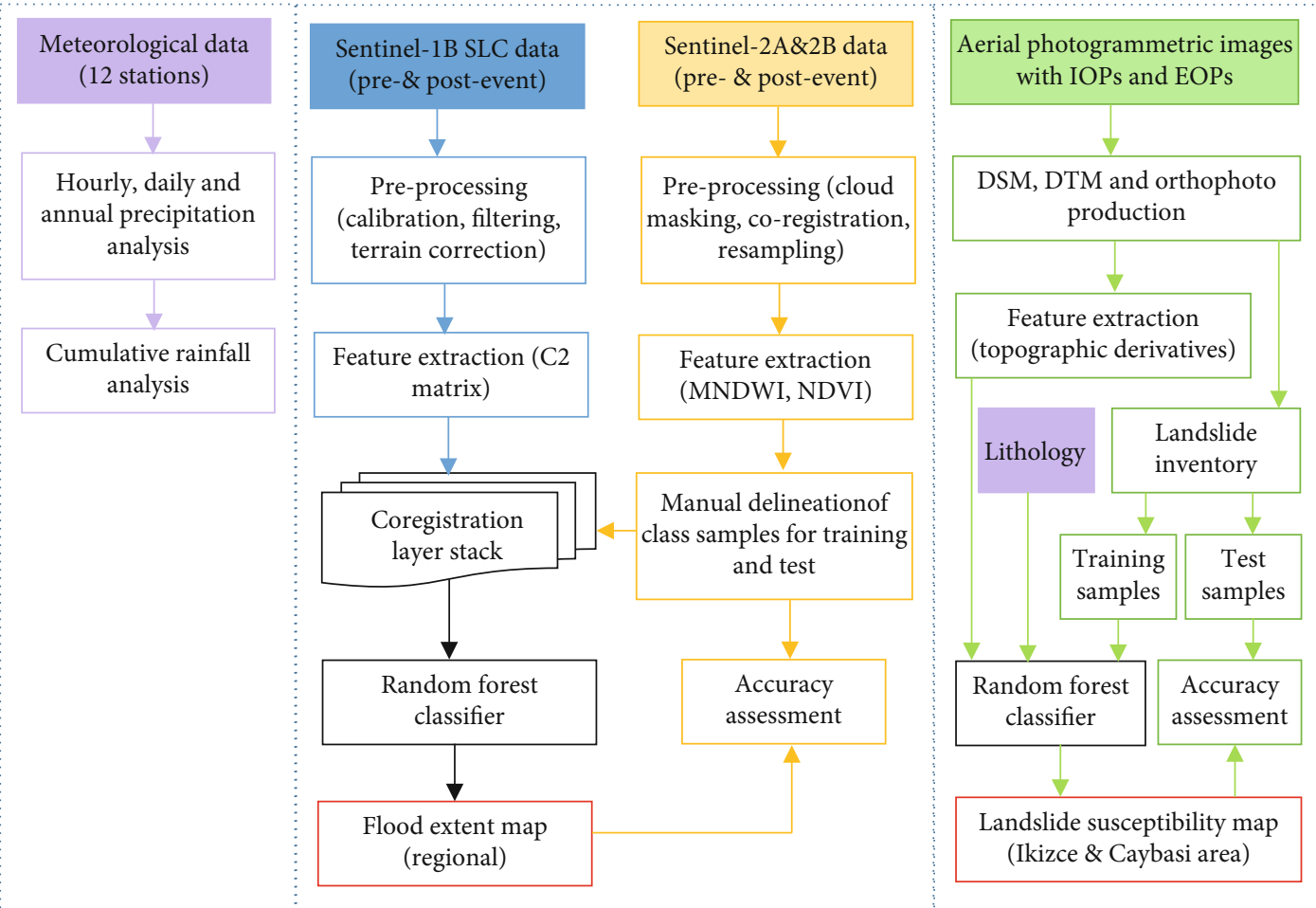

FIgURE 4: Overall methodological workflow of the study.

The study area is complex due to rugged topography and mixed land cover with inland water bodies (i.e., streams and rivers), urban settlements, open terrain, and agricultural and dense forest areas. Flood mapping using SAR data over hilly and mountainous areas has shortcomings due to the radar imaging principle, which cause geometric distortions such as layover, foreshortening, and shadows (no data areas). In addition, underwater vegetation and urban areas exhibit very complex signal returns due to multiple-bounce scattering. On the other hand, water surfaces can be easily detected due to low SAR backscattering. For these reasons, Polarimetric SAR (PolSAR) information was extracted and utilized together with SAR intensity information and with optical data for detecting flooded areas [54]. Single Look Complex (SLC) data of Sentinel-1 were used at the polarimetric decomposition stage. At this stage, the covariance matrix (C2) with a dimension of $2 \times 2$ method was extracted for polarimetric decomposition in SNAP. The matrix elements were postprocessed for despeckling with Improved Lee Sigma et al., 2009 [55]. The Lee sigma filter has been applied 


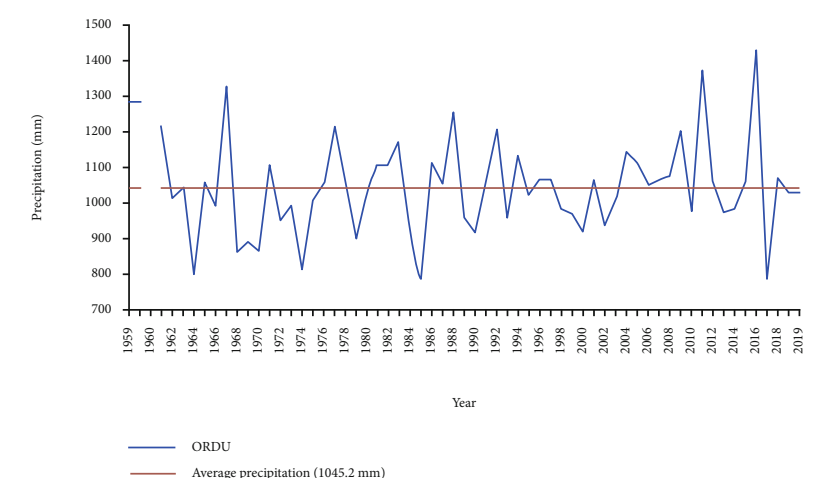

(a)

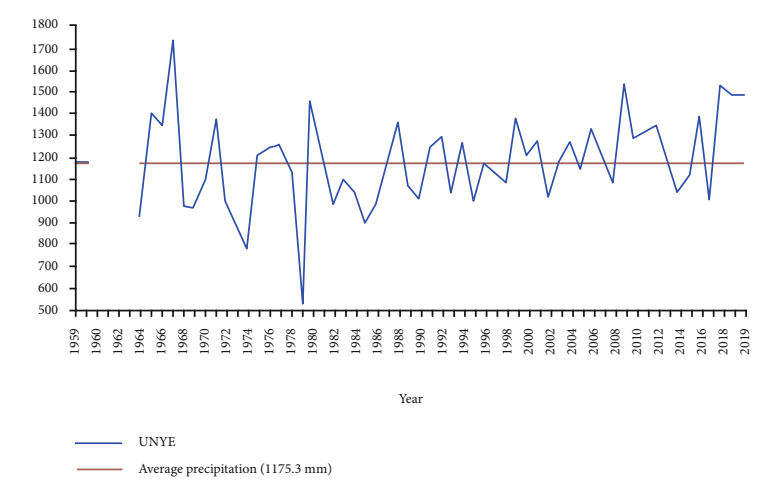

(b)

FIGURE 5: Long-term yearly precipitation statistics for (a) Ordu and (b) Unye Stations.

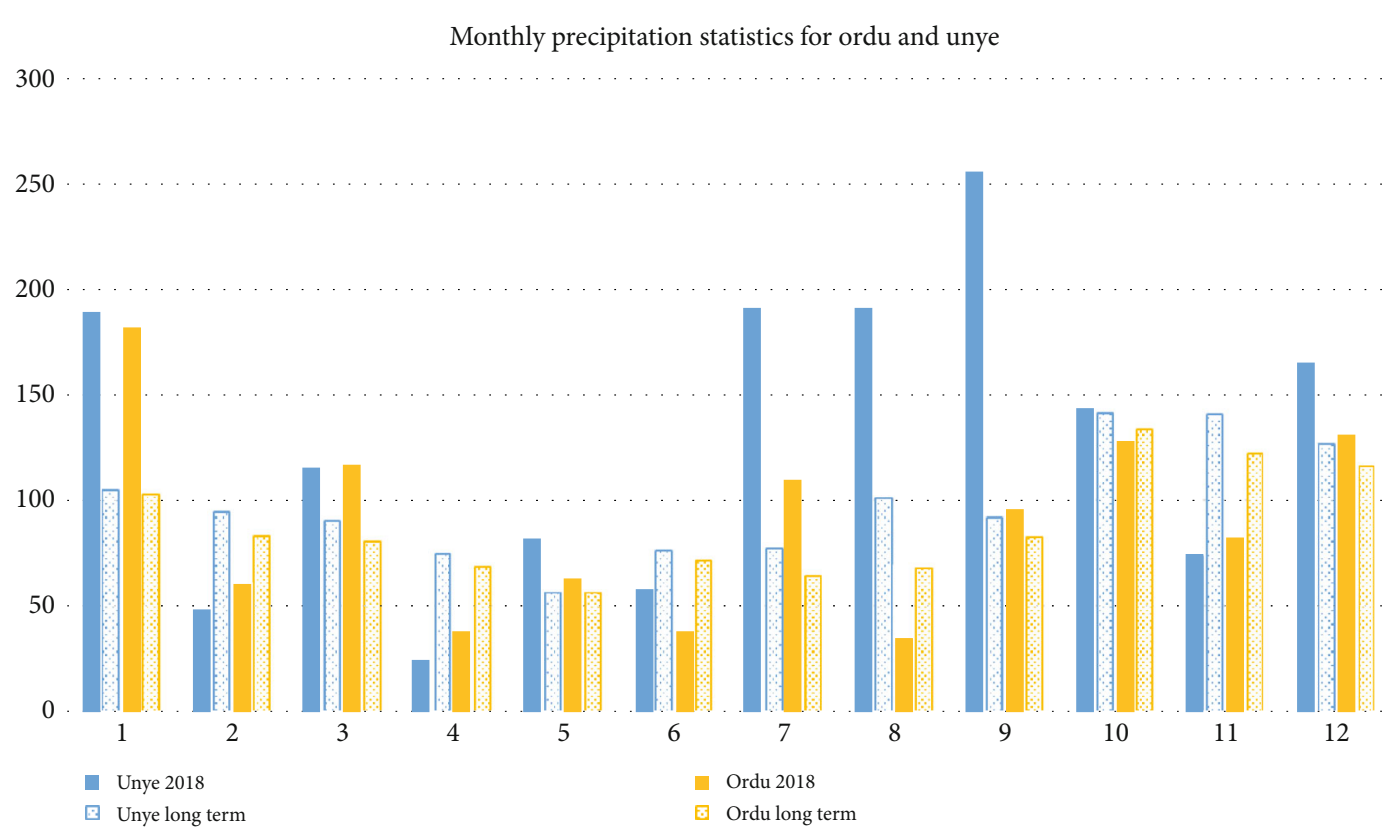

FIGURE 6: Long-term monthly averages and the precipitations in 2018 for Ordu and Unye.

in different studies and achieved successful results $[56,57]$ and was evaluated with different filter sizes by Tavus et al. [31] for flood extent mapping. Based on the visual checks, it was determined that $7 \times 7$ window size provided the best results. For these reasons, here, the Improved Lee Sigma filter, which solves the disadvantages of the Lee Sigma filter such as bias problem, was preferred and applied with $7 \times 7$ window size. Finally, the SAR dataset was terrain-corrected and orthorectified by using the Range Doppler Terrain Correction algorithm before performing the classification (see Figure 4).

On the other hand, both Sentinel-2 images were employed for extracting additional features on the land cover of the study area including flooded areas and for selecting training areas (polygons) for supervised classification of five classes (agriculture, urban area, flooded area, forest, and permanent water). The training polygons for all classes except the flood were delineated in DS4. The areas with flood were selected in DS3, which is partially cloudy, and the floodwater was still visible in some regions. In addition to the intensity data obtained from all 13 bands of Sentinel-2 sensors, NDVI (normalized difference vegetation index) and MNDWI (modified normalized difference water index) information were generated to be used as supplementary features to improve the classification. The MNDWI yields to better separation of settlement areas from water and employs short-wave infrared (SWIR) band instead of near-infrared (NIR) when compared with the normalized difference water index (NDWI) [58]. Here, DS3 was used particularly to select training samples for the flooded areas. The training polygons contain 8.782 pixels in urban, 8.212 pixels in permanent water, 84.048 pixels in forest, 2.636 pixels in flood, and 75.745 pixels in agriculture classes.

The random forest (RF), which is an ensemble ML technique of decision trees (DTs) [59], was used as the semisupervised classification method for the determination of the five classes in SNAP. In the RF method, the DTs were created randomly at the training stage and evaluated for the best score based on the average of the results of the trees. The $\mathrm{RF}$ is aimed at selecting the most important features when creating the DTs. Samples required for all classes for model 
Cumulative rainfall between 1-15 august, 2018

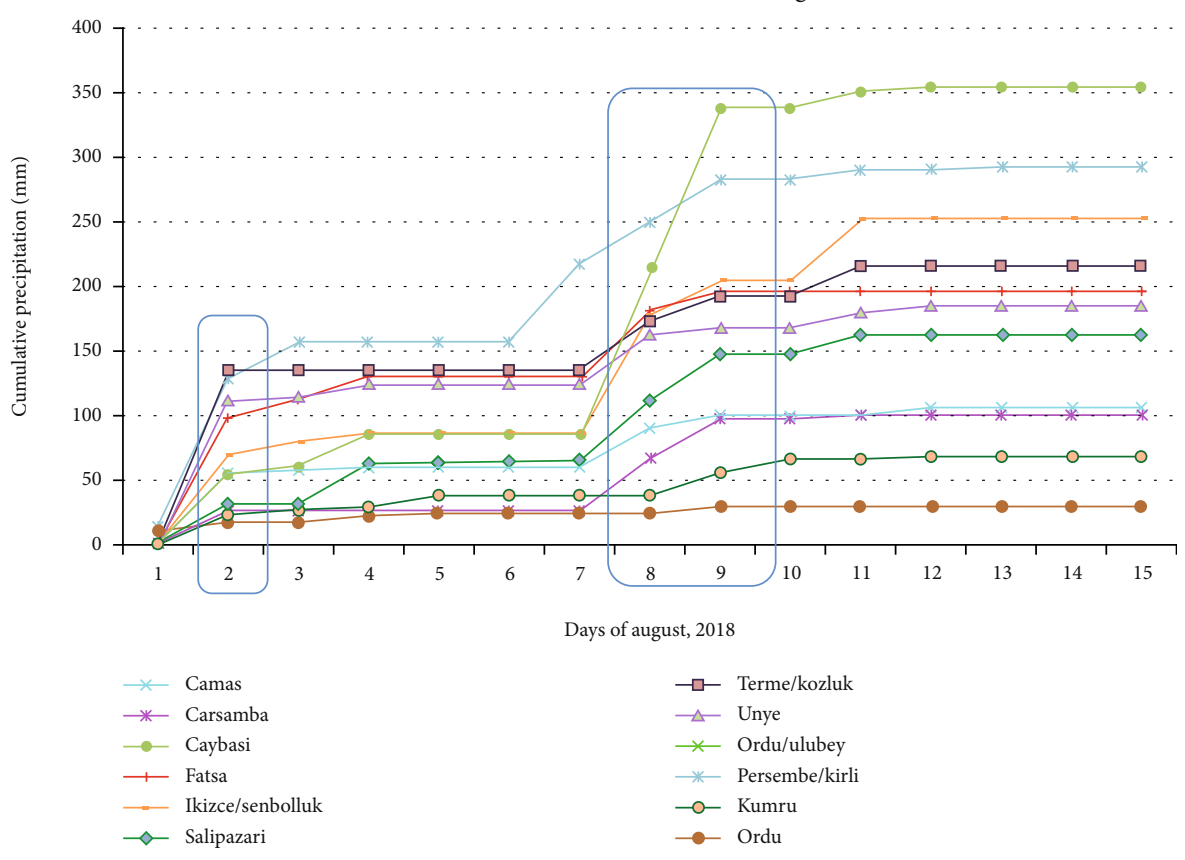

FIgURE 7: Cumulative rainfall in selected stations between 1 and 15 August 2018.
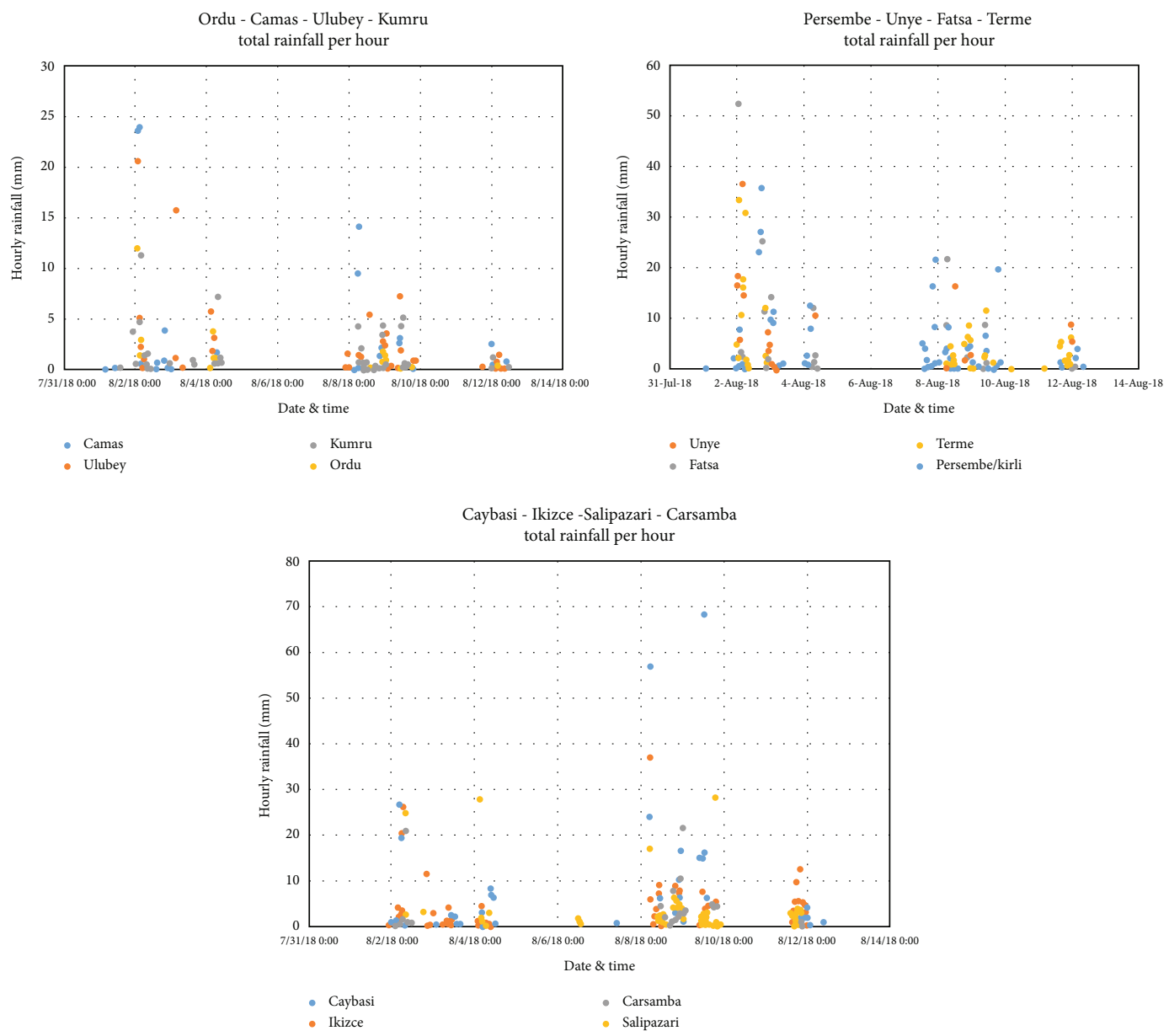

FIgURE 8: Hourly rainfall in selected stations between 1 and 15 August 2018. 


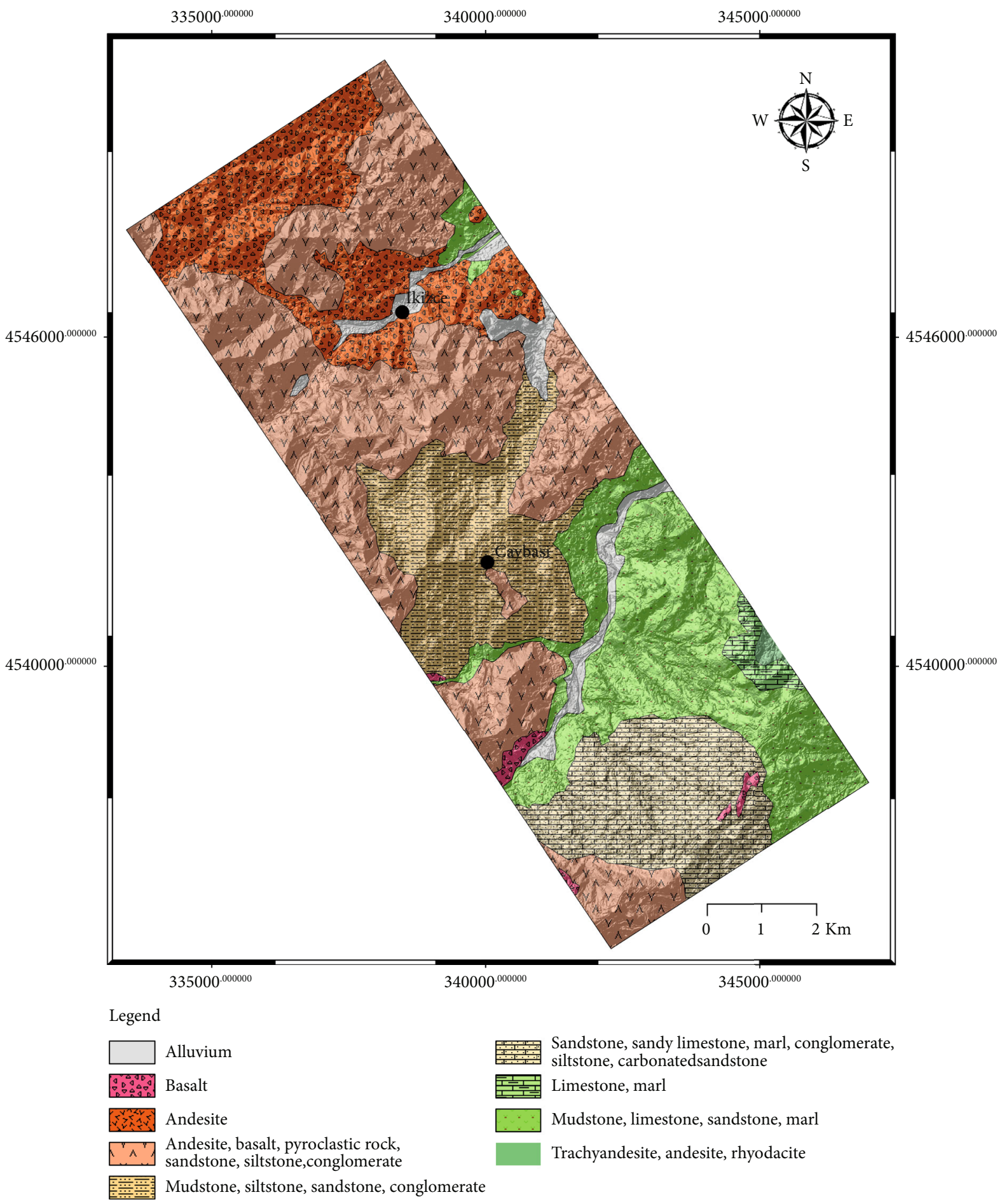

Figure 9: Lithological map of Ikizce-Caybasi area [46].

training were collected from all feature images, and the polygons of the representative areas were manually delineated in Sentinel-2 datasets (DS3 and DS4) as mentioned above.

3.3. Landslide Inventory and Susceptibility Mapping with Aerial Photogrammetry. Aerial photogrammetric datasets acquired on 17 August 2018 (after the flood) by the General Directorate of Mapping (GDM), Turkey, were used here for landslide inventory preparation and susceptibility assessment. 11 stereo images taken in a single strip over the Ikizce-Caybasi area, which was one of the most affected sites from landslides triggered by the intense and prolonged rainfall, were utilized for the investigations. The images were taken in four spectral bands (RGB and NIR) by using Ultracam Eagle camera produced by Vexcel Imaging, Austria, and have high spatial resolution $(30 \mathrm{~cm})$. The camera has a frame 


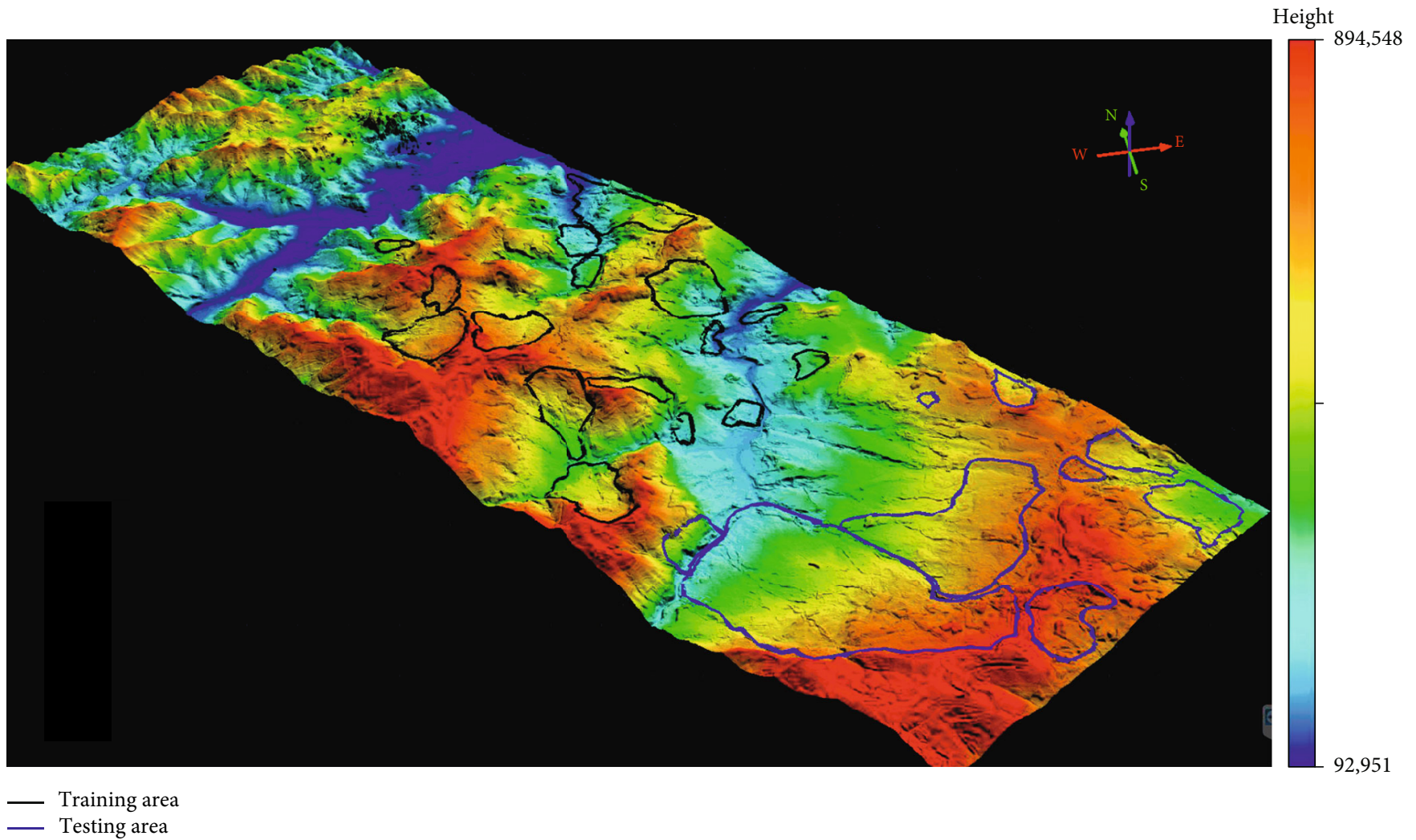

FIgURE 10: The DTM and the landslide inventory of Ikizce-Caybasi area.

TABLE 1: Descriptive statistics of the topographical data obtained for subarea and the area with landslide.

\begin{tabular}{|c|c|c|c|c|c|c|c|c|}
\hline \multirow{2}{*}{ Parameters } & \multicolumn{4}{|c|}{ Ikizce-Caybasi area } & \multicolumn{4}{|c|}{ Landslide inventory area } \\
\hline & Min & $\operatorname{Max}$ & Mean & Std. Dev. & Min & $\operatorname{Max}$ & Mean & Std. Dev. \\
\hline $\mathrm{DTM}(\mathrm{m})$ & 93.0 & 894.5 & 386.6 & 130.9 & 151.8 & 703.6 & 412.9 & 96.0 \\
\hline Slope gradient $\left({ }^{\circ}\right)$ & 0 & 86.9 & 23.1 & 13.9 & 0 & 77.1 & 17.6 & 12.3 \\
\hline Slope aspect $\left({ }^{\circ}\right)$ & -1 & 360 & 179.0 & 106.9 & -1 & 360 & 194.4 & 112.9 \\
\hline TWI & -3.16 & 25.31 & 4.29 & 2.45 & -1.70 & 25.23 & 4.55 & 2.65 \\
\hline Distance to drainage (m) & 0 & 1706.1 & 477.8 & 342.3 & 0 & 1661.8 & 406.7 & 300.7 \\
\hline Plan slope curvature & -3.73 & 6.35 & 3.50 & 7.91 & -1.22 & 1.44 & 3.58 & 6.60 \\
\hline Profile slope curvature & -4.41 & 5.17 & -8.81 & 6.14 & -2.30 & 1.93 & -1.54 & 6.10 \\
\hline
\end{tabular}

format of $20.010 \times 13.080$ pixels with $0.005 \mathrm{~mm}$ detector size and $100.5 \mathrm{~mm}$ focal distance. To produce the Digital Surface Model (DSM), Digital Terrain Model (DTM), and orthophotos, the interior and exterior orientation parameters, which were estimated in a bundle block adjustment process using GNSS surveyed ground control points at GDM, were employed in Trimble Inpho software [60]. The orthophotos and the grid DSM/DTM have resolutions of $30 \mathrm{~cm}$ and $1 \mathrm{~m}$, respectively, with a location accuracy of ca. $15 \mathrm{~cm}$ [61].

In the last few decades, the importance of landslide susceptibility assessments and mapping has increased significantly, and researchers using various methods have produced landslide susceptibility maps (e.g., [62, 63]). In the present study, landslide susceptibility evaluations were performed in the towns Ikizce and Caybasi in Ordu (see
Figures 1 and 9) because the most of landslides occurred in this part of the region at the same time with the flood as well. A total of 25 landslide polygons, which were delineated manually using the DSM and the orthophotos produced in the study, form the landslide inventory (Figure 10). The mass movements were classified as deep-seated circular active failures according to the characteristics published by Cruden and Varnes [64]. The polygon sizes range from $0.4 \mathrm{~km}^{2}$ to $5.4 \mathrm{~km}^{2}$, with a total area of $17 \mathrm{~km}^{2}$.

To assess the landslide susceptibility in the IkizceCaybasi area, the preparatory parameters were investigated. For this purpose, the lithological map and topographic factors with respect to landslides were assessed. The most prone lithologies observed in the subarea are weak sedimentary rocks and volcanic (see Figure 9). Approximately $40 \%$ of 


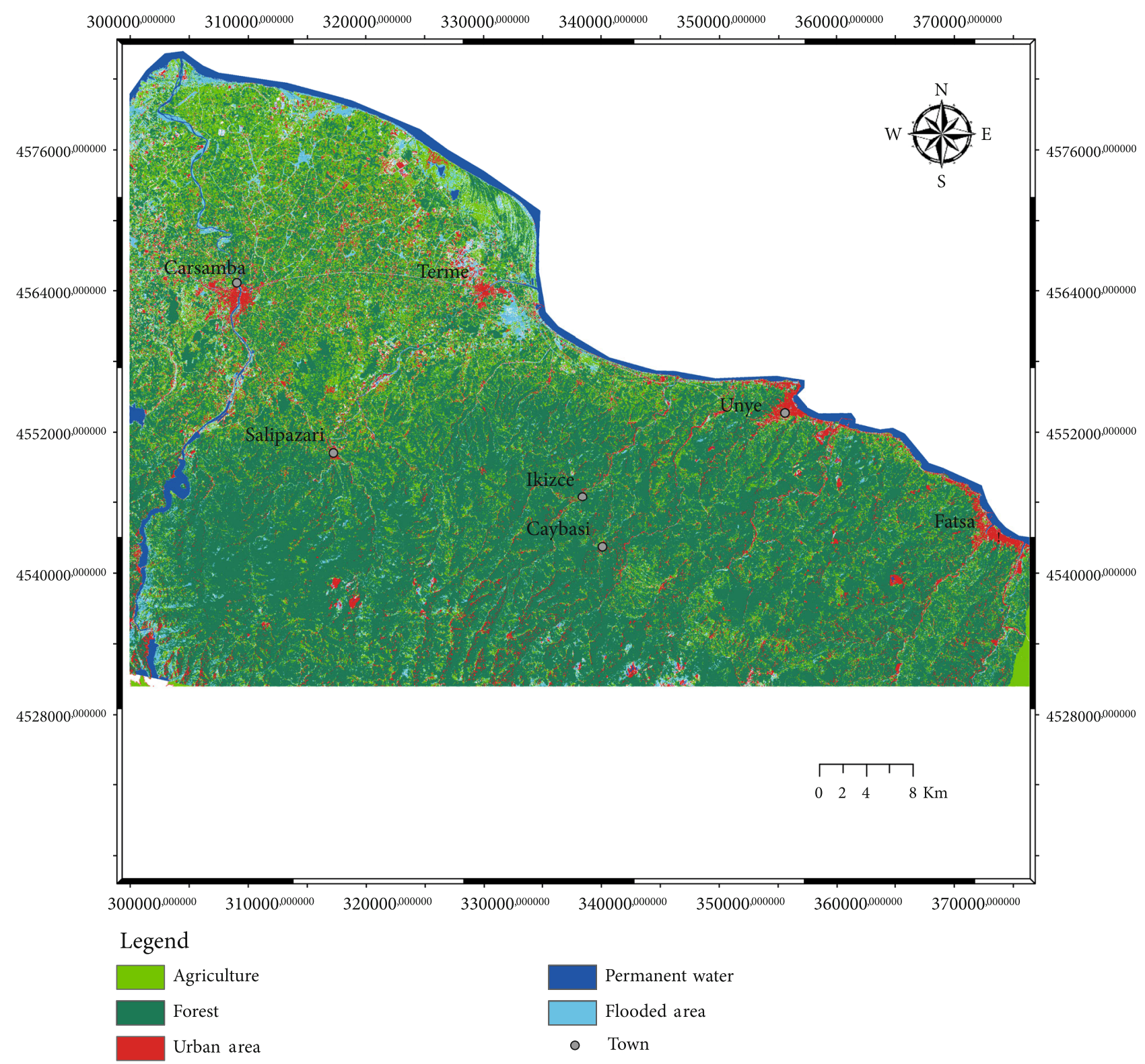

FIgURE 11: Result of the flood analysis produced for the whole area affected by flooding.

the landslides were observed in the weak claystonesandstone. $20 \%$ of the landslides were mapped on EarlyMiddle Eocene aged sandstone and mudstone, 20\% of the landslides were mapped on Maastrichtian-Palaeocene aged mudstone, limestone, sandstone, and marl, and $16 \%$ of the landslides mapped on Middle-Late Eocene aged andesite, basalt, and pyroclastic rocks. Six topographic parameters, altitude, slope gradient, slope aspect, plan and profile slope curvatures, topographic wetness index, and a hydrological factor distance to drainage network were evaluated as the landslide preparatory parameters in the region [61]. Descriptive statistics of these parameters for the subarea and the area with landslides were investigated, respectively (Table 1). As a result, the failures within the subarea are observed on the mean topographic slopes of $17^{\circ}$, in areas with a mean topographic wetness index (TWI) value of 4.55 , and at a mean distance of approximately $406 \mathrm{~m}$ from the drainage network as shown in Table 1.

The results of landslide susceptibility evaluations provide the first insight on the landslide-prone areas, which is particularly essential for acquiring rapid results when working with high-resolution datasets. Using the lithological map and topographic factors, the landslide susceptibility model of the subarea was produced with the RF method. The use of the RF method is rather new for landslide susceptibility modeling (e.g., [65-70]). Currently, there has been a significant increase in the implementation of ML algorithms for the production of landslide susceptibility maps. The major problems with the expert-based techniques, which can be considered as the alternative methods, are the time and labor-intensive processing and sometimes accessibility to the area. Here, the RF method was selected since it was found 


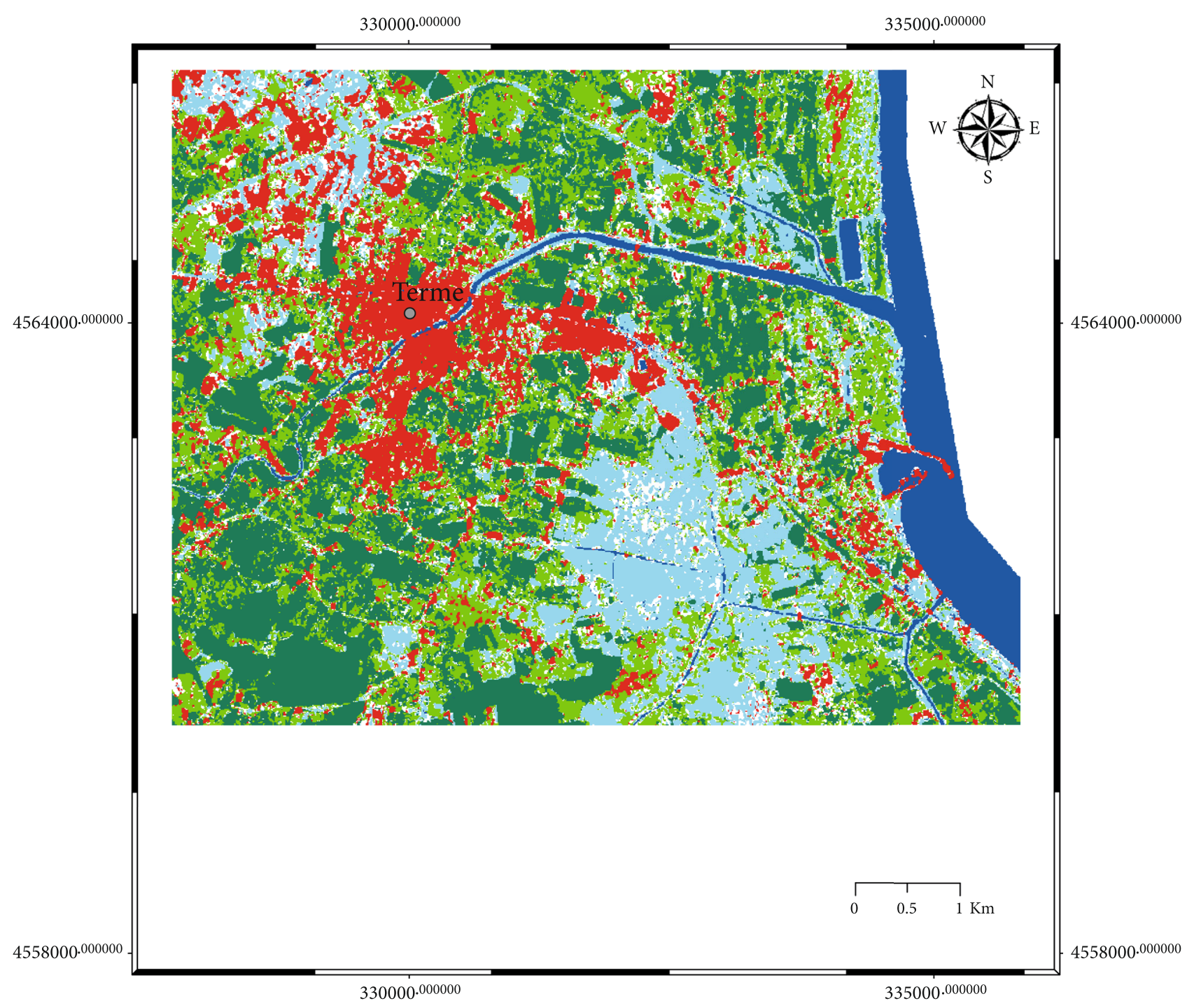

Legend

$\square$ Agriculture
Forest
Urban area

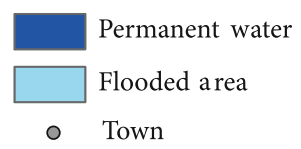

Figure 12: Result of the flood analysis produced for Terme subarea.

very effective among other ML algorithms by Sevgen et al. [69]. The landslide inventory data were used to train the model. For the model training, the landslide polygons were used with an 80/20 ratio. Owing to the imbalanced distribution of the landslides in the subarea, only the region in the middle part of the site (marked with black in Figure 10) was implemented for the model training. The larger landslides in the southern part of the subarea and the other landslides in the East were not employed in the model training stage but used for accuracy assessment. A total of 139,096,240 grid cells (8 feature classes each with pixels labelled as 6,954,812 landslide and 10,432,218 non-landslide) were implemented in the training stage. The total number of grid cells in the study area is 88.790 .485 . The receiver operat- ing characteristics (ROC) curves and the area under the curve (AUC) were used for accuracy assessment [71].

\section{Results and Discussion}

When the long-term annual precipitation data for Ordu and Unye were evaluated (Figure 5), it was observed that the variations between 2017-2018 and 2018-2019 were quite large. In 2017, the precipitation amount in Ordu was among the lowest since 1959. On the other hand, the precipitation in Unye in 2018 was among the highest from the beginning of the measurements. Having such high variations between different years may have triggered the floods. In addition, the monthly averages for Unye between July and September 


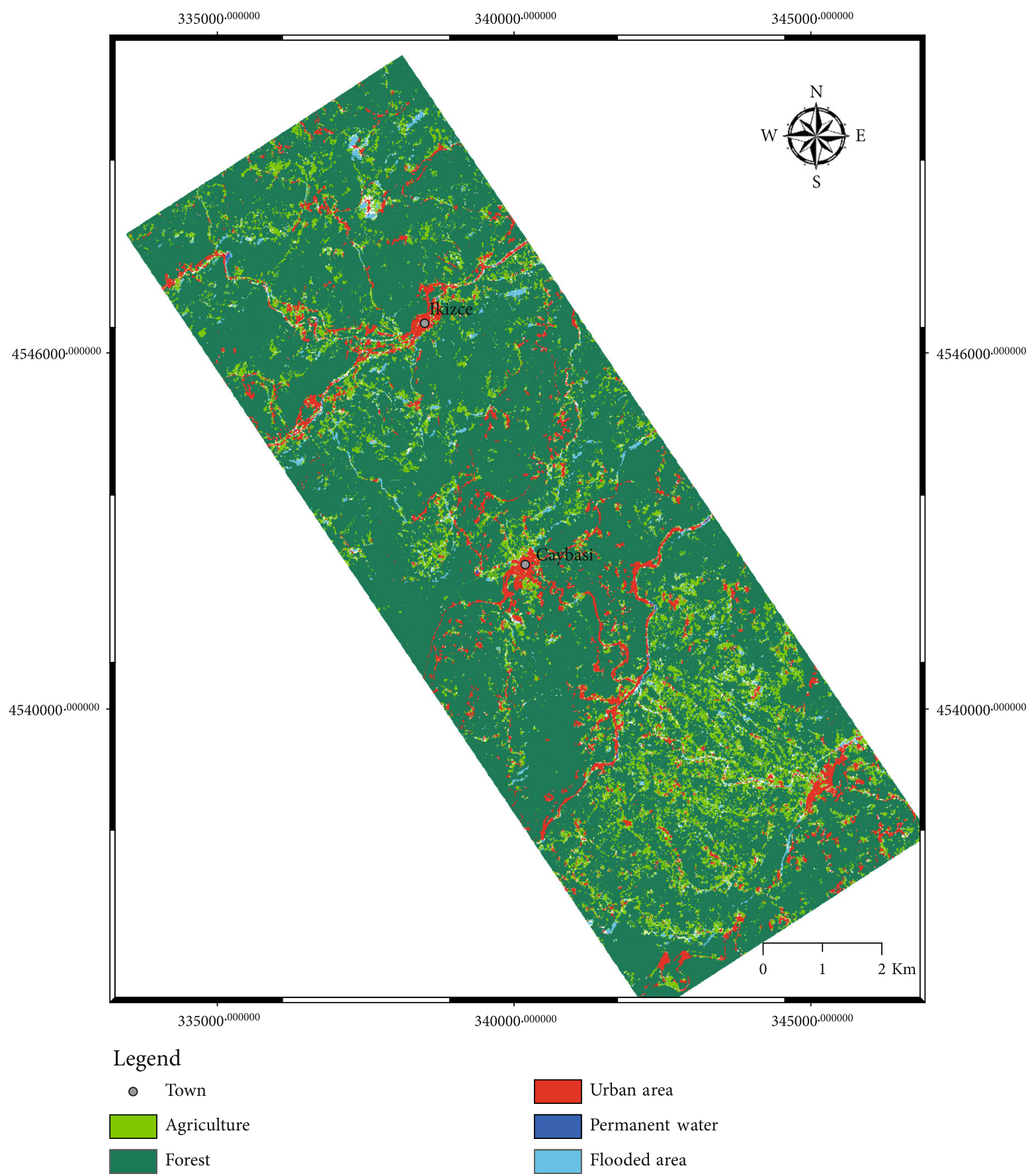

Figure 13: Result of the flood analysis produced for Ikızce-Caybası area.

2018 were up to 2.8 times when compared with the long-term monthly averages (Figure 6). This fact is not visible in Ordu monthly averages, since the annual precipitation of Ordu was very close to the long-term averages. When the cumulative data between 1 and 15 August (Figure 7) were considered, the extreme precipitation on August 2nd was followed by heavy rainfall on August 8th and 9th, which increased the destructive effects. In addition, the rainfall was concentrated in 2-3 hours at most on these days (Figure 8).

Figure 11 shows the RF classification results of the whole area affected by flooding. The flooded areas shown with cyan in the Figure correspond with the expectations based on the topography and evidenced by the damage reports. Although the settlement areas were classified correctly, the agricultural areas and forests could not be separated sufficiently especially in mountainous areas. One potential reason for this is radar shadows, which can be investigated in more detail in the future. The permanent water areas could be classified accurately thanks to the posthazard data of Sentinel-2 (DS4). The results were evaluated also for the two subparts: Terme area (Figure 12), which is plain and the floodwater remained longer, and Ikizce-Caybasi (Figure 13), which is the same area in which landslide susceptibility results were produced. The performance of the RF model developed within the 


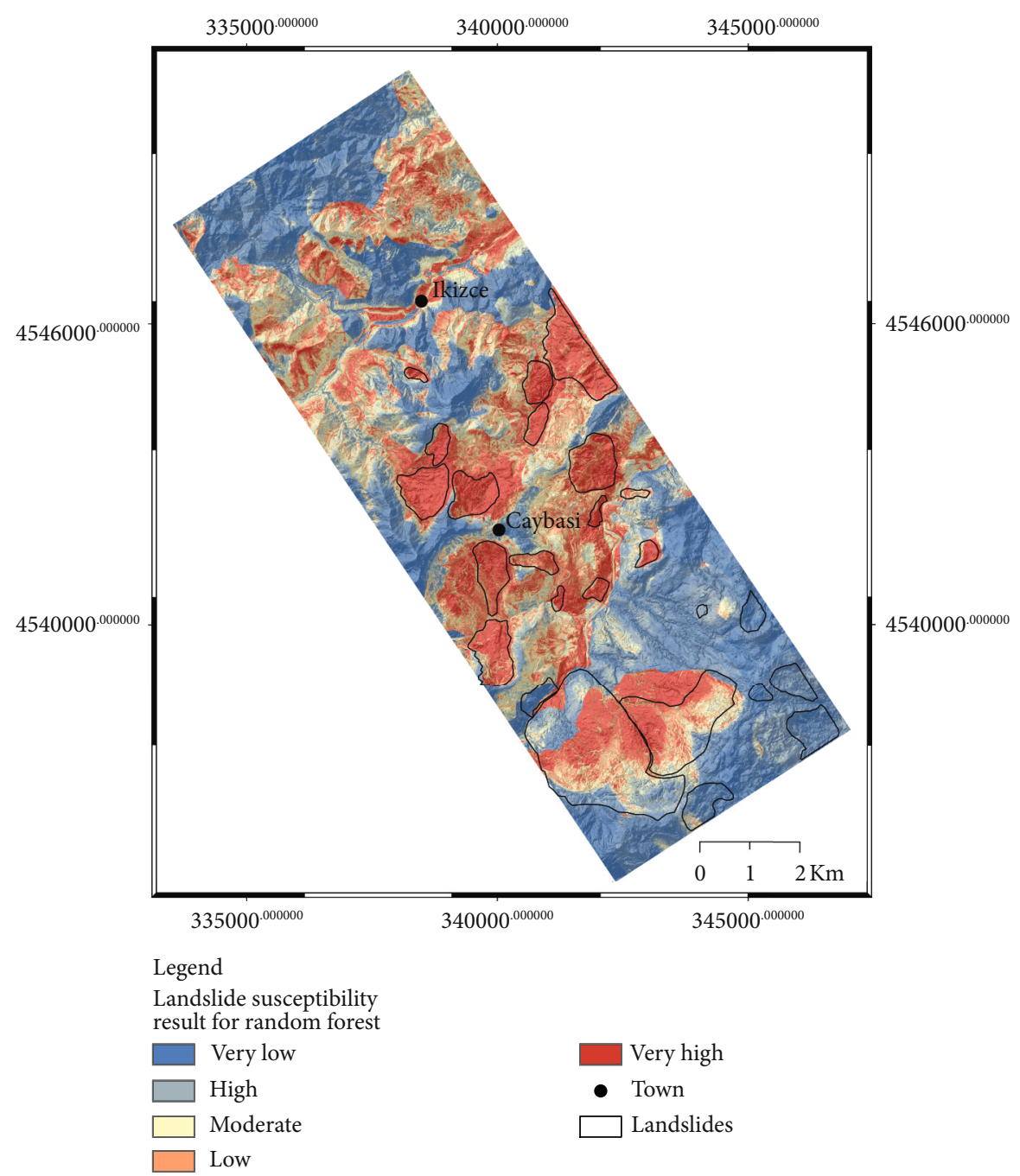

(a)

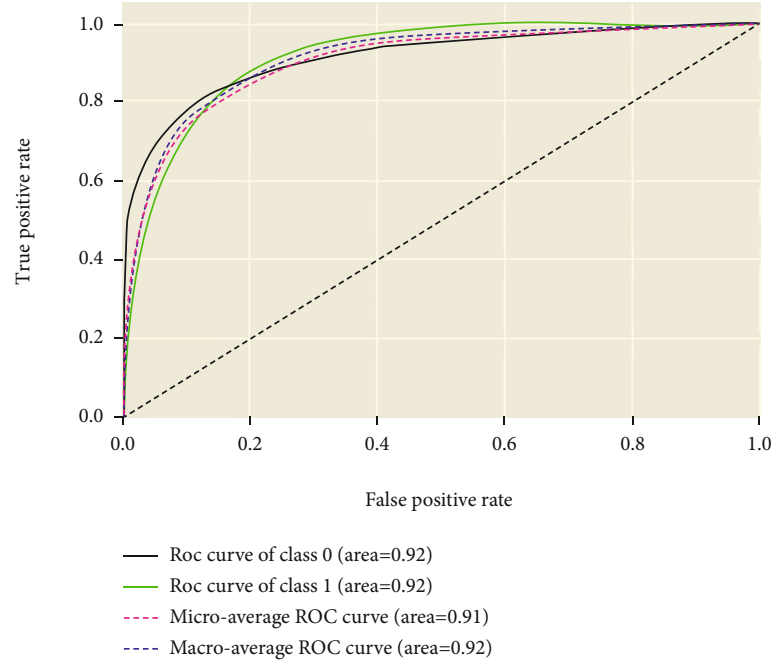

(b)

FIGURE 14: Landslide susceptibility map of Ikizce-Caybasi area (a) and the ROC curves obtained from the RF model (b). 
TABLE 2: The landslide probability distribution in Ikizce-Caybasi Area [61].

\begin{tabular}{lccc}
\hline Class & Probability range (\%) & Area $\left(\mathrm{km}^{2}\right)$ & Percentage \\
\hline Very high & $80-100$ & 3.4 & $3.9 \%$ \\
High & $60-80$ & 10.9 & $12.3 \%$ \\
Moderate & $40-60$ & 15.2 & $17.2 \%$ \\
Low & $20-40$ & 17.1 & $19.3 \%$ \\
Very low & $0-20$ & 42.1 & $47.4 \%$ \\
\hline
\end{tabular}

scope of the flood mapping was provided by the SNAP Tool and evaluated here by considering the correct classification percentage and accuracy statistics. Accordingly, the overall correct classification $\%$ of the model was $90.51 \%$, while the accuracy value calculated for the flood class in the model was 0.97 .

As one of the most landslide-prone area in Turkey, upto-date landslide susceptibility maps, which depict spatial probabilities for landslides likely to occur in the future, need to be produced for Ordu Province as a fundamental mitigation measure. On-demand aerial image acquisition for DSM and orthophoto production offers an advantage. The use of ML methods with high predictive capacity for landslide susceptibility model construction increases the reliability of these maps. The RF model training outputs were used for the whole subarea dataset to produce the resultant landslide susceptibility map (Figure 14(a)). The resultant landslide susceptibility map obtained by using the model was assessed in 5 equally divided classes as follows; very low, low, moderate, high, and very high (Table 2 ). The sizes of the areas with high and very high susceptibility values were $10.9 \mathrm{~km}^{2}$ and $3.4 \mathrm{~km}^{2}$, respectively.

The performance assessment of the model was investigated with the ROC curves and the AUC statistics. The test grid cells were implemented for the ROC curves. In the ROC curve evaluations, the classes 0 and 1 represent nonlandslide and landslide data, respectively. Accordingly, the AUC value was calculated to be 0.92 that means the prediction performance of the model is enough to estimate possible future landslides in the region (Figure 14(b)).

\section{Conclusions and Future Work}

In this study, a meteorological catastrophe that occurred in Ordu in August 2018 was assessed in terms of precipitation data, and landslide susceptibility and flood extent maps by using multitemporal and multisource optical and radar datasets. The present study also summarizes a meteorological catastrophe and its harmful consequences. The long- and short-term precipitation data analysis indicated large yearly and monthly variations in the regions and heavy rainfall over a few hours. Depending on climate change, a further increase in the frequencies of such catastrophic events is expected. To reduce the harmful effects of these catastrophes, the consequences should be understood clearly and the necessary precautions must be considered.

Here, aerial photogrammetric images acquired after the event were utilized for landslide inventory mapping and sus- ceptibility evaluation. Sentinel-1 SAR and Sentinel-2 optical EO data were fused at feature level for the flood extent mapping. A semisupervised ML method, RF, was used both for the landslide susceptibility assessment and the flood mapping. Regarding flood extent mapping using radar and optical EO data by feature-level fusion with the RF method, the results were found suitable for the purposes. High revisit time and availability of Sentinel-1 SAR and Sentinel-2 optical imageries are advantageous for disaster management purposes. In addition, the capabilities of the freely available SNAP Tool ensure usability of the data by different organizations and professionals from various disciplines. However, the application of the processing algorithm requires some level of expertise and standardized methods for this purpose can aid nonexperienced users. The training data required by the supervised classification method were delineated manually on the optical dataset, and the same areas could be used in SAR images, which showed the potential of the combined use of both sensors after geometric preprocessing. Although no fieldwork could be conducted up to date, they may help to assist the determination of the actual land use and the assessment of the ground conditions.

Regarding the landslide susceptibility mapping, the manual interpretation of landslides requires high expertise and is a time-consuming process for engineering geologists and geomorphologists. The development of automated or semiautomated techniques can increase efficiency by decreasing the processing time and operator bias. Landslide inventory preparation is essential to analyze their mechanisms and to predict the landslide hazard and risk. This task is nowadays supported by the EO data with diverse spatial, spectral, and temporal resolutions. However, the development of new processing methods is crucial to handle the increasing complexity of the data obtained from different sensors, to reduce the requirement for computational sources, and to achieve high performance. In future work, the landslide susceptibility map will be expanded to the other parts of the region based on aerial image availability before and after the extreme rainfall. In addition, rule sets will be developed for performing a rule-based classification to increase the generalization potential. Integrated multihazard assessment is also required, and methods for this purpose will also be integrated as suggested by Yanar et al. [72].

\section{Data Availability}

The aerial photogrammetric data that was used in this study are available from General Directorate of Mapping, Turkey, but restrictions apply to the availability of these data, which were used under a bilateral agreement for the current study, and so are not publicly available. The Sentinel-1 and Sentinel-2 data are provided freely by European Space Agency Copernicus Open Access Hub.

\section{Conflicts of Interest}

The authors declare that they have no conflicts of interest. 


\section{Acknowledgments}

The authors gratefully thank to General Directorate of Mapping, Turkey, for the provision of aerial photogrammetric datasets; and Dr. Orhan Firat and Recep Can for their kind support.

\section{References}

[1] CRED (Centre for Research on the Epidemiology of Disasters) and UNDRR (UN Office for Disaster Risk Reduction, "The human cost of disasters: an overview of the last 20 years (2000-2019)," 2020, October 2020, https://reliefweb.int/ report/world/human-cost-disasters-overview-last-20-years2000-2019.

[2] A. J. Breugem, J. G. Wesseling, K. Oostindie, and C. J. Ritsema, "Meteorological aspects of heavy precipitation in relation to floods - an overview," Earth-Science Reviews, vol. 204, p. 103171, 2020.

[3] L. Li, Y. Zou, Y. Li et al., "Trends, change points and spatial variability in extreme precipitation events from 1961 to 2017 in China," Hydrology Research, vol. 51, no. 3, pp. 484-504, 2020.

[4] P. Jyoteeshkumar, P. V. Kiran, and C. Balaji, "Chennai extreme rainfall event of 2015 under future climate projections using the pseudo global warming dynamic downscaling method," Current Science, vol. 118, no. 12, p. 1968, 2020.

[5] A. N. Comin, F. Justino, L. Pezzi et al., "Extreme rainfall event in the Northeast coast of Brazil: a numerical sensitivity study," Meteorology and Atmospheric Physics, 2020.

[6] C. Gokceoglu, H. Sonmez, H. A. Nefeslioglu, T. Y. Duman, and T. Can, "The 17 March 2005 Kuzulu landslide (Sivas, Turkey) and landslide- susceptibility map of its near vicinity," Engineering Geology, vol. 81, no. 1, pp. 65-83, 2005.

[7] T. Can, H. A. Nefeslioglu, C. Gokceoglu, H. Sonmez, and T. Y. Duman, "Susceptibility assessments of shallow earthflows triggered by heavy rainfall at three catchments by logistic regression analyses," Geomorphology, vol. 72, no. 1-4, pp. 250-271, 2005.

[8] Z. Li, F. Zhang, W. Gu, and M. Dong, “The Niushou landslide in Nanjing City, Jiangsu Province of China: a slow-moving landslide triggered by rainfall," Landslides, vol. 17, no. 11, pp. 2603-2617, 2020.

[9] F. Ocakoglu, C. Gokceoglu, and M. Ercanoglu, "Dynamics of a complex mass movement triggered by heavy rainfall: a case study from NW Turkey," Geomorphology, vol. 42, no. 3-4, pp. 329-341, 2002.

[10] M. Diakakis, N. Boufidis, J. M. Salanova Grau, E. Andreadakis, and I. Stamos, "A systematic assessment of the effects of extreme flash floods on transportation infrastructure and circulation: the example of the 2017 Mandra flood," International Journal of Disaster Risk Reduction, vol. 47, p. 101542, 2020.

[11] S.-J. Park and D.-K. Lee, "Prediction of coastal flooding risk under climate change impacts in South Korea using machine learning algorithms," Environmental Research Letters, vol. 15, no. 9, article 094052, 2020.

[12] A. Quesada-Roman and A. Villalobos-Chacon, "Flash flood impacts of hurricane Otto and hydrometeorological risk mapping in Costa Rica," Danish Journal of Geography, vol. 120, no. 2, pp. 142-155, 2020.

[13] P. Billi, Y. T. Alemu, and R. Ciampalini, "Increased frequency of flash floods in Dire Dawa, Ethiopia: change in rainfall inten- sity or human impact?," Natural Hazards, vol. 76, no. 2, pp. 1373-1394, 2015.

[14] C. Mbow, A. Diop, A. T. Diaw, and C. I. Niang, "Urban sprawl development and flooding at Yeumbeul suburb (Dakar-Senegal)," African Journal of Environmental Science and Technology, vol. 2, pp. 75-88, 2008.

[15] K. Mishra and R. Sinha, "Flood risk assessment in the Kosi megafan using multi-criteria decision analysis: a hydrogeomorphic approach," Geomorphology, vol. 350, p. 106861, 2020.

[16] T. Schmitt, M. Thomas, and N. Ettrich, "Analysis and modeling of flooding in urban drainage systems," Journal of Hydrology, vol. 299, no. 3-4, pp. 300-311, 2004.

[17] AFAD, "Ministry of interior-disaster and emergency management presidency," April 2020 https://www.afad.gov.tr/.

[18] J. C. Chen, W. S. Huang, and Y. F. Tsai, "Variability in the characteristics of extreme rainfall events triggering debris flows: a case study in the Chenyulan watershed, Taiwan," Natural Hazards, vol. 102, no. 3, pp. 887-908, 2020.

[19] X. Fan, J. Tang, S. Tian, and Y. Jiang, "Rainfall-induced rapid and long-runout catastrophic landslide on July 23, 2019 in Shuicheng, Guizhou, China," Landslides, vol. 17, no. 9, pp. 2161-2171, 2020.

[20] J. P. García-Garrido, M. C. Gallego, T. Palacios, R. M. Trigo, and J. M. Vaquero, "Heavy rainfall and landslide event in January 1831 at the Pedregoso Mountains (Cabeza Del Buey, SW Spain)," Atmosphere, vol. 11, no. 5, p. 544, 2020.

[21] S. Ma, C. Xu, X. Xu et al., "Characteristics and causes of the landslide on July 23, 2019 in Shuicheng, Guizhou Province, China," Landslides, vol. 17, no. 6, pp. 1441-1452, 2020.

[22] E. K. Bessette-Kirton, J. A. Coe, W. H. Schulz, C. CerovskiDarriau, and M. M. Einbund, "Mobility characteristics of debris slides and flows triggered by hurricane Maria in Puerto Rico," Landslides, vol. 17, no. 12, pp. 2795-2809, 2020.

[23] M. Ouled Sghaier, I. Hammami, S. Foucher, and R. Lepage, "Flood extent mapping from time-series SAR images based on texture analysis and data fusion," Remote Sensing, vol. 10, no. 2, p. 237, 2018.

[24] G. L. Feyisa, H. Meilby, R. Fensholt, and S. R. Proud, "Automated water extraction index: a new technique for surface water mapping using Landsat imagery," Remote Sensing of Environment, vol. 140, pp. 23-35, 2014.

[25] B. C. Ko, H. H. Kim, and J. Y. Nam, "Classification of potential water bodies using Landsat 8 OLI and a combination of two boosted random forest classifiers," Sensors, vol. 15, no. 6, pp. 13763-13777, 2015.

[26] C. J. Van der Sande, S. M. De Jong, and A. P. J. De Roo, “A segmentation and classification approach of IKONOS-2 imagery for land cover mapping to assist flood risk and flood damage assessment," International Journal of Applied Earth Observation and Geoinformation, vol. 4, no. 3, pp. 217-229, 2003.

[27] I. Nandi, P. K. Srivastava, and K. Shah, "Floodplain mapping through support vector machine and optical/infrared images from Landsat 8 OLI/TIRS sensors: case study from Varanasi," Water Resources Management, vol. 31, no. 4, pp. 1157-1171, 2017.

[28] X. Tong, X. Luo, S. Liu et al., "An approach for flood monitoring by the combined use of Landsat 8 optical imagery and COSMO-SkyMed radar imagery," ISPRS Journal of Photogrammetry and Remote Sensing, vol. 136, pp. 144-153, 2018. 
[29] R. Oberstadler, H. Hönsch, and D. Huth, "Assessment of the mapping capabilities of ERS-1 SAR data for flood mapping: a case study in Germany," Hydrological Processes, vol. 11, no. 10, pp. 1415-1425, 1997.

[30] P. Nakmuenwai, F. Yamazaki, and W. Liu, "Automated extraction of inundated areas from multi-temporal dual-polarization RADARSAT-2 images of the 2011 Central Thailand flood," Remote Sensing, vol. 9, no. 1, p. 78, 2017.

[31] B. Tavus, S. Kocaman, C. Gokceoglu, and H. A. Nefeslioglu, "Considerations on the use of Sentinel-1 data in flood mapping in urban areas: Ankara (Turkey) 2018 floods," ISPRS International Archives of the Photogrammetry, Remote Sensing and Spatial Information Sciences, vol. XLII-5, no. 5, pp. 575581, 2018.

[32] L. Pulvirenti, N. Pierdicca, M. Chini, and L. Guerriero, "Monitoring flood evolution in vegetated areas using COSMOSkyMed data: the Tuscany 2009 case study," IEEE Journal of Selected Topics in Applied Earth Observations and Remote Sensing, vol. 6, no. 4, pp. 1807-1816, 2013.

[33] B. Tavus, S. Kocaman, H. Nefeslioğlu, and C. GÖKÇEOĞLU, "Flood mapping using Sentinel-1 SAR data: a case study of Ordu 8 august 2018 floodInternational Journal of Environment and Geoinformatics," vol. 6, no. 3, pp. 333-337, 2019.

[34] L. Pulvirenti, M. Chini, N. Pierdicca, L. Guerriero, and P. Ferrazzoli, "Flood monitoring using multi-temporal COSMO-SkyMed data: image segmentation and signature interpretation," Remote Sensing of Environment, vol. 115, no. 4, pp. 990-1002, 2011.

[35] P. Matgen, R. Hostache, G. Schumann, L. Pfister, L. Hoffmann, and H. H. G. Savenije, "Towards an automated SAR-based flood monitoring system: lessons learned from two case studies," Physics and Chemistry of the Earth, Parts $A / B / C$, vol. 36, no. 7-8, pp. 241-252, 2011.

[36] L. Giustarini, R. Hostache, P. Matgen, G. J. P. Schumann, P. D. Bates, and D. C. Mason, "A change detection approach to flood mapping in urban areas using TerraSAR-X," IEEE Transactions on Geoscience and Remote Sensing, vol. 51, no. 4, pp. 2417-2430, 2013.

[37] Y. Bazi, L. Bruzzone, and F. Melgani, “An unsupervised approach based on the generalized Gaussian model to automatic change detection in multitemporal SAR images," IEEE Transactions on Geoscience and Remote Sensing, vol. 43, no. 4, pp. 874-887, 2005.

[38] P. Lal, A. Prakash, A. Kumar et al., "Evaluating the 2018 extreme flood hazard events in Kerala, India," Remote Sensing Letters, vol. 11, no. 5, pp. 436-445, 2020.

[39] ESA Sentinel, 2020, October 2020, https://sentinel.esa.int/web/ sentinel/home.

[40] A. Akgun, E. A. Sezer, H. A. Nefeslioglu, C. Gokceoglu, and B. Pradhan, "An easy-to-use MATLAB program (MamLand) for the assessment of landslide susceptibility using a Mamdani fuzzy algorithm," Computers and Geosciences, vol. 38, no. 1, pp. 23-34, 2012.

[41] H. A. Nefeslioglu and C. Gokceoglu, "Probabilistic risk assessment in medium scale for rainfall-induced earthflows: Catakli catchment area (Cayeli, Rize, Turkey)," Mathematical Problems in Engineering, vol. 2011, 21 pages, 2011.

[42] H. A. Nefeslioglu, B. T. San, C. Gokceoglu, and T. Y. Duman, "An assessment on the use of Terra ASTER L3A data in landslide susceptibility mapping," International Journal of Applied Earth Observation and Geoinformation, vol. 14, no. 1, pp. 4060, 2012 .
[43] C. E. Uyeturk, N. Huvaj, H. Bayraktaroglu, and M. Huseyinpasaoglu, "Geotechnical characteristics of residual soils in rainfall-triggered landslides in Rize, Turkey," Engineering Geology, vol. 264, p. 105318, 2020.

[44] A. Demir, H. G. Ilgen, and A. Isik, Ordu İlinde, 04-06/07/2016 Tarihleri Arasinda Meydana Gelen Sel-Taşkin-Su Baskini Ve Heyelan Olaylarinin Genel Değerlendirmesi, Presentation at 4. Ulusal Taşkın Sempozyumu, 21-24 November, Rize, Turkey, 2016.

[45] B. Akbas, N. Akdeniz, A. Aksay et al., Geological Map of Turkey -1:1.250.000, General Directorate of Mineral Research and Exploration, Ankara, Turkey, 2011.

[46] I. E. Altun, Maden Tetkik Ve Arama Genel Müdürlüğü 1:100000 ölçekli Türkiye Jeoloji Haritaları F38 Ve G38 Paftalarl, no:151, General Directorate of Mineral Research and Exploration, Ankara, Türkiye, 2011.

[47] AMS (American Meteorological Society), "Glossary of meteorology, Rain. Archived from the original on 2010-07-25," 2000, https://www.ametsoc.org/ams/index.cfm/publications/ glossary-of-meteorology/.

[48] T. R. T. News, "Ordu'da Sel Felaketi. Online news portal of Turkish radio television agency on 8 august 2018," 2018, May 2020, https://www.trthaber.com/haber/turkiye/ordudasel-felaketi-379211.html.

[49] ESA, "Copernicus open access hub," 2020, July 2020, https:// scihub.copernicus.eu.

[50] ESASNAP, “Sentinel application platform," 2020, July 2020, https://step.esa.int/main/toolboxes/snap/.

[51] T. Nagler, H. Rott, E. Ripper, G. Bippus, and M. Hetzenecker, "Advancements for snowmelt monitoring by means of Sentinel-1 SAR," Remote Sensing, vol. 8, no. 4, p. 348, 2016.

[52] ESA Sentinel-2, 2020, July 2020, https://sentinel.esa.int/web/ sentinel/missions/sentinel-2.

[53] M. Pandžic, D. Mihajlovic, J. Pandžic, and N. Pfeifer, "Assessment of the geometric quality of Sentinel-2 DATA," ISPRS International Archives of the Photogrammetry, Remote Sensing and Spatial Information Sciences, vol. XLI-B1, pp. 489-494, 2016.

[54] B. Tavus, S. Kocaman, H. A. Nefeslioglu, and C. Gokceoglu, "A fusion approach for flood mapping using Sentinel-1 and Sentinel-2 datasets," ISPRS - International Archives of the Photogrammetry, Remote Sensing and Spatial Information Sciences, vol. XLIII-B3-2020, pp. 641-648, 2020.

[55] J. S. Lee, J. H. Wen, T. L. Ainsworth, K. S. Chen, and A. J. Chen, "Improved sigma filter for speckle filtering of SAR imagery," IEEE Transactions on Geoscience and Remote Sensing, vol. 47, no. 1, pp. 202-213, 2009.

[56] J. S. Lee and E. Pottier, Polarimetric Radar Imaging: From Basics to Applications. In Optical Science and Engineering, CRC Press, Boca Raton, FL, USA, 2009.

[57] J. Jaybhay and R. Shastri, "A study of speckle noise reduction filters," Signal \& Image Processing : An International Journal, vol. 6, no. 3, pp. 71-80, 2015.

[58] H. Xu, "Modification of normalised difference water index (NDWI) to enhance open water features in remotely sensed imagery," International Journal of Remote Sensing, vol. 27, no. 14, pp. 3025-3033, 2007.

[59] L. Breiman, "Random forests," Machine Learning, vol. 45, no. 1, pp. 5-32, 2001.

[60] Trimble, "Inpho photogrammetry suite," 2020, April 2020, https://geospatial.trimble.com/products-and-solutions/inpho. 
[61] G. Karakas, R. Can, S. Kocaman, H. A. Nefeslioglu, and C. Gokceoglu, "Landslide susceptibility mapping with random forest model for Ordu, Turkey," ISPRS - International Archives of the Photogrammetry, Remote Sensing and Spatial Information Sciences, vol. XLIII-B3-2020, pp. 1229-1236, 2020.

[62] H. Shahabi and M. Hashim, "Landslide susceptibility mapping using GIS-based statistical models and remote sensing data in tropical environment," Scientific Reports, vol. 5, no. 1, p. 9899, 2015.

[63] D. Tien Bui, H. Shahabi, A. Shirzadi et al., "Landslide detection and susceptibility mapping by AIRSAR data using support vector machine and index of entropy models in Cameron Highlands, Malaysia," Remote Sensing, vol. 10, no. 10, p. $1527,2018$.

[64] D. M. Cruden and D. J. Varnes, "Landslide types and processes," in Landslides: investigation and mitigation, A. K. Turner and R. L. Schuster, Eds., pp. 36-75, Transportation Research Board, National Research Council (NRC), 1996, rep 247.

[65] W. Chen, X. Xie, J. Wang et al., “A comparative study of logistic model tree, random forest, and classification and regression tree models for spatial prediction of landslide susceptibility," Catena, vol. 151, pp. 147-160, 2017.

[66] L. Chu, L. J. Wang, J. Jiang, X. Liu, K. Sawada, and J. Zhang, "Comparison of landslide susceptibility maps using random forest and multivariate adaptive regression spline models in combination with catchment map units," Geosciences Journal, vol. 23, no. 2, pp. 341-355, 2019.

[67] J. Dou, A. P. Yunus, D. Tien Bui et al., "Assessment of advanced random forest and decision tree algorithms for modeling rainfall-induced landslide susceptibility in the IzuOshima Volcanic Island, Japan," Science of the Total Environment, vol. 662, pp. 332-346, 2019.

[68] H. Y. Hong, H. R. Pourghasemi, and Z. S. Pourtaghi, "Landslide susceptibility assessment in Lianhua County (China): a comparison between a random forest data mining technique and bivariate and multivariate statistical models," Geomorphology, vol. 259, pp. 105-118, 2016.

[69] E. Sevgen, S. Kocaman, H. A. Nefeslioglu, and C. Gokceoglu, "A novel performance assessment approach using photogrammetric techniques for landslide susceptibility mapping with logistic regression, ANN and random forest," Sensors, vol. 19, no. 18 , p. $3940,2019$.

[70] T. Yanar, S. Kocaman, and C. Gokceoglu, "On the use of Sentinel-2 images and high resolution DTM for landslide susceptibility mapping in a developing urban settlement (Mamak, Ankara, Turkey)," ISPRS - International Archives of the Photogrammetry, Remote Sensing and Spatial Information Sciences, vol. XLII-3/W8, pp. 469-476, 2019.

[71] J. Swets, "Measuring the accuracy of diagnostic systems," Science, vol. 240, no. 4857, pp. 1285-1293, 1988.

[72] T. Yanar, S. Kocaman, and C. Gokceoglu, "Use of Mamdani fuzzy algorithm for multi-Hazard susceptibility assessment in a developing urban settlement (Mamak, Ankara, Turkey)," ISPRS International Journal of Geo-Information, vol. 9, no. 2, p. $114,2020$. 